\title{
Testing Engine Oil Specifications and Properties and its Effects on the Engines Maintenance and Performance
}

\author{
MOHANNAD O. RAWASHDEH, SAYEL M. FAYYAD, AHMAD S. AWAD \\ Al-Balqa Applied University, Faculty of Engineering Technology Department of Mechanical \\ Engineering \\ Amman, JORDAN
}

\begin{abstract}
The key significant material in internal combustion engines and hydraulic machines are the working fluid or the oil. Oil types and characteristics have a significant effect on engine functions, performance, and life. Stability of oil properties is critical for engines and equipment in movement. The degree of stability of oils properties is significant since if oil loses its optimum properties, mechanical and chemical excessive corrosion of the motor metals may occur. Consequently, damage occurs to one or more parts of the engine, thereby the system is breaking down where the cost of downtime is too expensive. This paper presents the main experimental results of mechanical tests on oil's specifications and characteristics and their effect on the overall efficiency. It has been found that a higher viscosity value is not the best as it value since it increases temperature and energy consumption due to viscous frictional losses. The values required for viscosity is the ideals that gives the stable results regardless temperature and pressure variations and under any conditions of operation, at which the power losses are minimal and the fuel economy is optimal.
\end{abstract}

Key-Words: - engine oil, fluid properties, performance, internal combustion engines, wear and viscosity.

Received: November 1, 2019. Revised: May 26, 2020. Revised: June 1, 2020. Revised: June 24, 2020. Accepted: June 25, 2020. Published: June 26, 2020.

\section{Introduction}

The most important material in combustion engines and hydraulic machines is the oil. Oil is used to grease moving parts, seal clearances between rotating mechanisms, coupling parts and dissipate heat. It acts as an effective medium for power transmission with efficient operation. Clean, ideal quality oil is required to achieve efficient hydraulic system operation [1]. The oils in hydraulic machines operate under high pressure and different operating temperatures. The oil must maintain an ideal viscosity during its time of operation were the system performance is mostly depends on temperature and the working period [2]. The main problems occurs in hydraulic systems and engines is directly linked to oils. In the case that the oil loses its viscosity, the leaked oil will cause pressure loss leading to breakdown the machine where the cost of downtime is prohibitive [1]. Reliability, capability, and execution of the current engines are direct depending upon the ampleness of greasing up and oil systems. To be practical, an engine greasing up frameworks ought to, successfully, play out the components of restricting the scouring between the surfaces of moving parts, and decrease the wear due to metal-to-metal contact
[3]. And dispersing warmth, and keeping the engine parts clean by ousting carbon and other outside issues. Right now in combustion motors, the framework that gives the lube to these limits is the obliged oil structure. Notwithstanding the way that there are various assortments in lubing up structures for inside start motors, the parts and technique for action are essentially equivalent. The upper chamber surface with an assortment of wrinkles has been structure for this entertainment. For each chamber, four various ranges of segment plan at the upper chamber is utilized to look at the warm effect on the chamber head and engine oil temperature. Performance levels of engine oil depends on how much oil is given and how the oil is dealt with under the warm pile of the moving parts. This state of oil is immovably related to the shielded movement of an engine and its lifetime. Right now, basically improved informative method has been required by engine organizers. Right now are performed on the engine oils and their specific and limits [4].

Engine oil does some basic capabilities to give satisfactory greases. It tries to keep the engine perfect and free from rust and wear. It works as a coolant and sealant. It gives an oily film pad that reduces friction of the metal, thus 
consequently diminishing grinding and wear [1], [5]. These are just the fundamental elements of oil that differ according to their applications and operating conditions. It is the specific requests of a given application and the exceptional conditions under which oil is utilized that to a great extent decide the various extra capacities oil must perform. These extra capacities make picking the right oil for the activity indispensable [5].

\subsection{Engine oil types, usage and properties}

The types of oils that have been tested are listed in Table 1. Which presents the codes, properties and functions of the tested oils. These oils have been selected based on their significance and widespread use in Jordan. Its viscosity has been tested during operation and energy losses have been calculated [5].

Table 1 Types of engine oil tested and their characteristics [5].

\begin{tabular}{|l|l|}
\hline Oil type & Characteristics \\
\hline Fully synthetic \\
\hline $0 \mathrm{~W}-30$ & Fuel economy savings \\
\hline $0 \mathrm{~W}-40$ & $\begin{array}{l}\text { Enhance engine performance and power } \\
\text { Protect engine from wear and deposit } \\
\text { build-up }\end{array}$ \\
\hline $5 \mathrm{~W}-40$ & $\begin{array}{l}\text { Quick cold weather starting and fast } \\
\text { protection, extend engine life and in quick } \\
\text { circulation in freezing temperatures }\end{array}$ \\
\hline Semi-synthetic \\
\hline $5 \mathrm{~W}-30$ & $\begin{array}{l}\text { Better protection since it clean up sludge } \\
\text { left in the engine }\end{array}$ \\
\hline $10 \mathrm{~W}-40$ & $\begin{array}{l}\text { Good protection at the pickup time "the } \\
\text { first 10 min" and reducing engine wear }\end{array}$ \\
\hline $15 \mathrm{~W}-40$ & $\begin{array}{l}\text { It stabiles for long time, which increase oil } \\
\text { life and change intervals }\end{array}$ \\
\hline Mineral & $\begin{array}{l}\text { It has the ability to protect several types of } \\
\text { engines }\end{array}$ \\
\hline $10 \mathrm{~W}-40$ & $\begin{array}{l}\text { It has higher viscosity, requires changes } \\
\text { regularly }\end{array}$ \\
\hline $15 \mathrm{~W}-40$ \\
\hline
\end{tabular}

Oil is to dissipate heat and lubricate the metal to metal moving parts of the machine framework [1]. This is characterized by reducing friction and making the surface too smooth leading to decrease its heat generated. This also reduces pressure and vibrations, which reduces the general framework erosion. It is done by reducing its warm life so wear and improving its performance and productivity $[1,13]$. Oils may contain added substances known as grinding modifiers that synthetically tie to metal surfaces to decrease surface erosion in any event [5], [6], when there is lacking mass ointment present for hydrodynamic grease. Oils may contain additives known as grinding modifiers that synthetically bound to metal surfaces to reduce surface wear when there is a lack of mass ointment for hydrodynamic grease. Gas and liquid ointments can transfer heat. However, fluid grease is significantly more applicable by virtue of their high explicit warmth limit [7]. Regularly, liquid grease is continuously circulated from the cooler part of the frame, despite the fact that ointments may be used for heating as they are used for cooling when a directed temperature is required. In addition, this cycle stream determines the warmth scale that is converted in a random unit of time. High stream frameworks can transform a ton of warmth and have the extra advantage of diminishing the warm weight on the oil [5]. Among the details of primary motor oils is the thickness, which is an essential property of motor oils [8]. The thickness determination is mainly dependent on the overall temperature at which the engine starts and runs. If relevant exhibition standards are monitored, engines can be operated with single rating and multi-grade oils, depending on the application. Standard qualities are shown to the greatest possible degree in each thickness in [1].

\section{Effects of Engine Oil on Engine Performance and Oil Testing}

Different additives is added to improve oil desired specifications and features such as lubricity, viscosity, incompressibility, nontoxicity, chemical stability, fire resistance ... etc [1]. By the time, engine oil specifications and features are tested periodically to avoid engine troubleshooting due to long operation, fluid breakdown and contamination [1]. Oil checking, testing and analysing are the key part of effective condition to observe project effectiveness [9]. It may be utilized as a prescient and proactive apparatus to distinguish the wear methods of scouring parts and analysing the shortcomings in hardware. [10]. It is a technique for anticipating the wellbeing of gear in a non-nosy way, by the investigation of wear particles. The nonstop slanting of wear rate screens the presentation of motor/motor parts and gives early admonition and finding. Oil condition checking can detect risk sooner than 
Vibration system [11]. This strategy holds useful for both oil and oil tests. By investigating the oil test, the lingering life of utilized oil is resolved and a flaw in the machine can be analysed before the machine must be rashly closed down. Sliding glue wear particles are found in most greasing up oils. They are a sign of typical wear. The point here is to order every one of these specifics as indicated by their morphological characteristics of size, shape, edge subtleties thickness proportion, shading surface and by utilizing this grouping there by foresee wear disappointment modes in the motor and used this data to keep the motor from conceivable future difficulty. So right now is certain that the point of this venture is to lessen upkeep work which in term additionally diminish all the consumption which are utilized for keep up a Vehicle's motor in a working capable condition [12]. An examination by [14] got ready for depicting the lead of used engine oils all through their organization life subject to scouring and wear estimations with oil tests from three vague light-commitment directimbuement supercharged diesel engines. It was found that there is a strong connection between oil organization life and boron content, similarly as the destructive number and base number. A practically identical connection between the coefficient of scouring with used models and boron content similarly as silt content was viewed. Wolak (2018) portrayed the strategies of debasement of five engine oils having a spot with the equal SAE thickness class anyway moved by different creators. The procured results have provoked the headway of a truthful model enabling to find out ordinary perceptive estimations of the full scale destructive number for a given mileage. The results may urge dynamic as for the organization life of engine oils [15].

\subsection{Testing Method: Spectrometric Oil Analysis Programs}

A spectrophotometer is a gadget to measure light force at various frequencies. It creates light with a light source, and after the light goes through a subject, the light is diffracted into a range which is recognized by a sensor and deciphered into results we can utilize. The yield of a spectrophotometer is generally a chart of light power versus frequency. It is a support device which is utilized to check the state of the oil greased up mechanical frameworks (Examples: Motors, Engines, Gear boxes, Hydraulic frameworks). The frameworks can be held under observation without destroying them. Strangely worn mixes can be restricted and supplanted before a disastrous disappointment happens. The amount and sort of wear metals in test of greasing up oil is resolved. The amount can demonstrate something about the extent of the wear and the kind of wear metals can uncover which segment is wearing out. Information gathered to produce this diagram can normally be spared as a table of frequencies $[16,17]$.

\subsection{Method Description}

Spectrophotometer oil analysis is perhaps one of the more commonly used techniques for the determination of certain elements by either atomic emission or atomic absorption spectroscopy. While the techniques is readily automated to achieve a fast throughput of sample 1,2 and has morphology of the wear debris and is sensitive to particles sizes $10 \mathrm{~mm}$ [14].

\subsection{Spectrophotometer Instrument}

A radiation detector (phototube) to convert the radiant energy received to a measurable signal; and a readout device that displays the signal from the detector. See Figures. 1 and 2. These instruments are designed to work either as direct-flow capillaries or as reverse-flow capillaries. For the direct-flow capillaries, the sample reservoir is positioned below the measuring marks. For the reverse-flow capillaries, it is located above the marks. Opaque liquids can be tested using the reverse-flow capillaries, and some can have a third measuring mark. Having three measuring marks provides two subsequent flow times and improves the measurement repeatability [18].

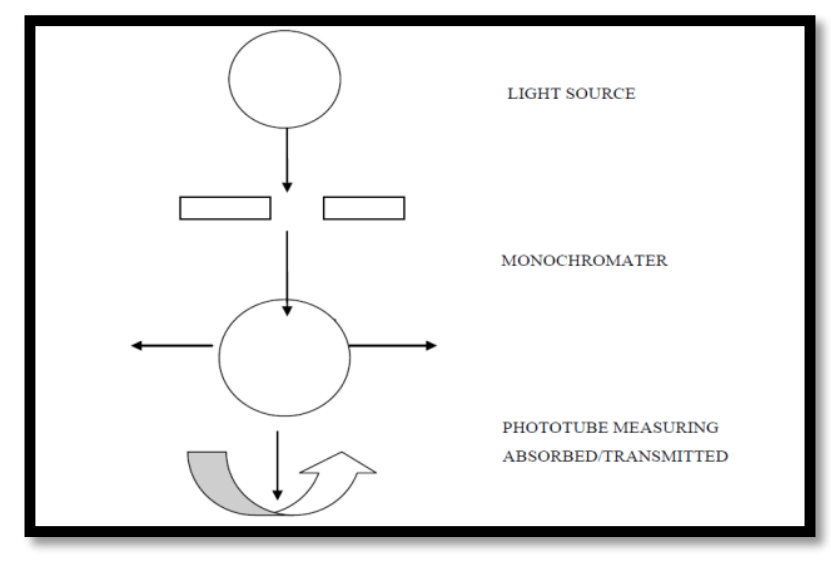

Figure 1: Schematic diagram showing the Component of Spectrophotometer. 


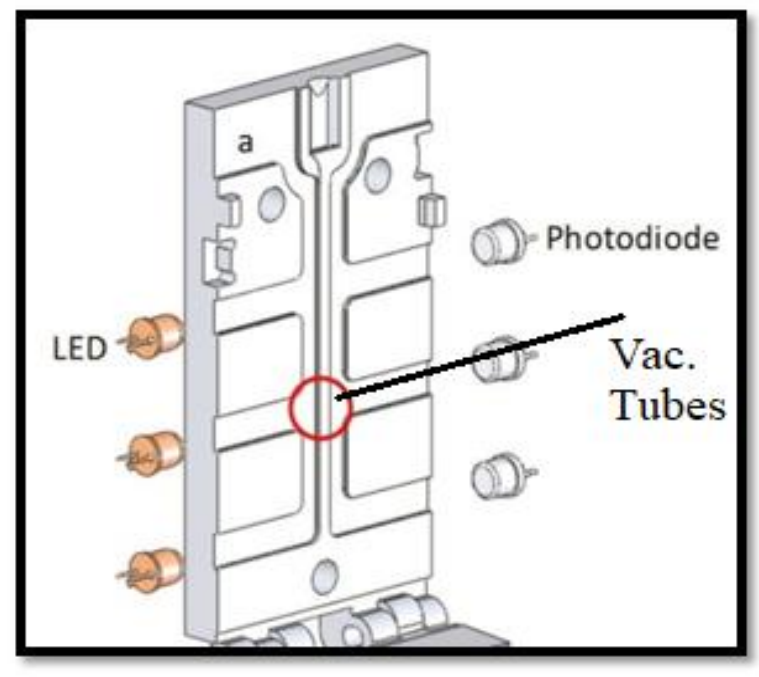

Figure (2) Spectrometer device used in the present study

\subsection{Working principle}

At the point when a light emission light goes through a straightforward medium, some portion of the light is retained and the transmitted shaft has a lower power than the force of the occurrence bar. Arrangements are set in holders (called "cuvettes") whose material is straightforward: quartz is regularly utilized, however for obvious light, one likewise utilizes expendable corvettes made of polystyrene or polycarbonate. The Transmittance, $\mathrm{T}$ of the arrangement is characterized by the proportion of the light power of the transmitted pillar, I to the power, Io of the episode bar-equation (1) below. It depends on the physical and chemical properties of the medium through which the light is traveling.

The relation quantify the Transmittance, $\mathrm{T}$ of the arrangement which characterized by the proportion of the light power of the transmitted pillar is

$$
T=I / I_{0}
$$

The absorbance, $\alpha$ is defined as, $\alpha=-\log _{10} \mathrm{~T}$. Since $\alpha$ is a logarithmic function, it is dimensionless.

The Beer-Lambert law states that the absorbance is directly proportional to the path length, $\ell$ of the sample and its concentration $c$. These relations are usually written as:

$$
\alpha=\log _{10}\left\lfloor\frac{I}{I_{0}}\right\rfloor=\varepsilon l c
$$

Where: $\varepsilon=$ molar absorptivity (with units of $\left(\mathrm{mol}^{-1}\right.$ $\left.\mathrm{cm}^{-1}\right), \ell=$ path length of the sample i.e. the path length of the cuvette in which the sample is contained and $\mathrm{c}=$ concentration of the compound in solution, expressed in $\mathrm{mol} \mathrm{L}^{-1}$ [19-21].

\section{Results and Discussion}

Some results from the first approach are summarized in Figures 3, 4 and 5. The results from the GM FLARE software for a 5.0 litter gasoline engine for an SAE- 10W/30 engine oil are shown in Figure 3. The results show power unit loss (J/revolution) as a function of the engine speed (RPM) for four parts in which mechanical losses due to viscous effect were concentrated in the engine: piston skirt, bearings, piston rings and piston trains. The results show the power unit loss increases by the speed. It is due to the direct relation between pressure and discharge, which reflects the direct relation between discharge and engine speed. The pressure is also increased by the increase the dynamic pressure head due to increase in flow velocity. The Frictional Mean Effective Pressure (FMEP) measured in Figure 3 at 2000 and 5000 RPM are 54.8 and $76.4 \mathrm{kPa}$ respectively. The higher values of FMEP resulted in reducing efficiency and increasing power loss.

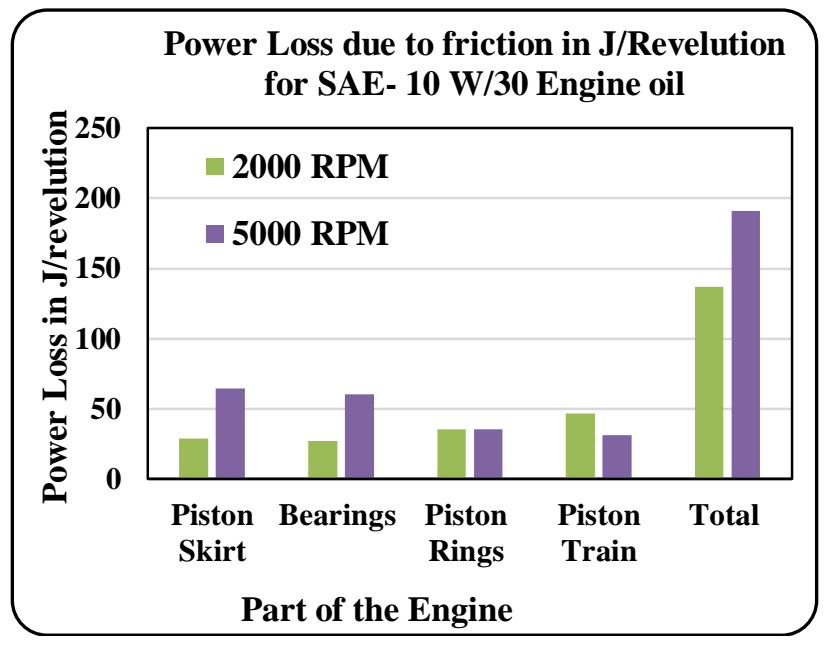

Figure 3: Results from GM FLARE software for a 5.0 litter gasoline engine for an SAE- 10W/30 engine oil 
Figure 4 shows the results for Leeds University total engine friction model as applied to a Ford Zetec 1.8 litter gasoline engine (lubricant not specified). From Figures 3 and 4, the power unit loss measured is significantly higher for higher speeds. The two speeds chosen to test the power loss of engine different components were 2000 and 5000 RPM.

From Figure 3, the values of power unit losses were higher for piston skirt (64 J/revolution) and bearing component (60 J/revolution) at $5000 \mathrm{RPM}$. The piston rings did not show this same variation despite the speed various conditions. This higher amount of energy loss will increase the heat generated, the oil temperature and affects its properties such as its ideal viscosity. This again affects its performance, practical appropriately and reliably. Further heat loss leads to a decrease in the viscosity of the oil, which leads to increase oil leakage through the seals and breakdown the oil layer between the moving parts in dynamic applications [1].

Figure 4 shows the effect of power unit loss as a function of speed is significant, It has a double acting effect: on the kinetic energy loss and the Frictional Mean Effective Pressure. The Frictional Mean Effective Pressure (FMEP) measured in Figure 4 at 2000 and $5000 \mathrm{RPM}$ are 73.4 and $78.6 \mathrm{kPa}$ respectively. The higher value of FMEP resulted in higher pressure drop through valves and lines and high temperatures caused by pressure, so higher power loss [1].

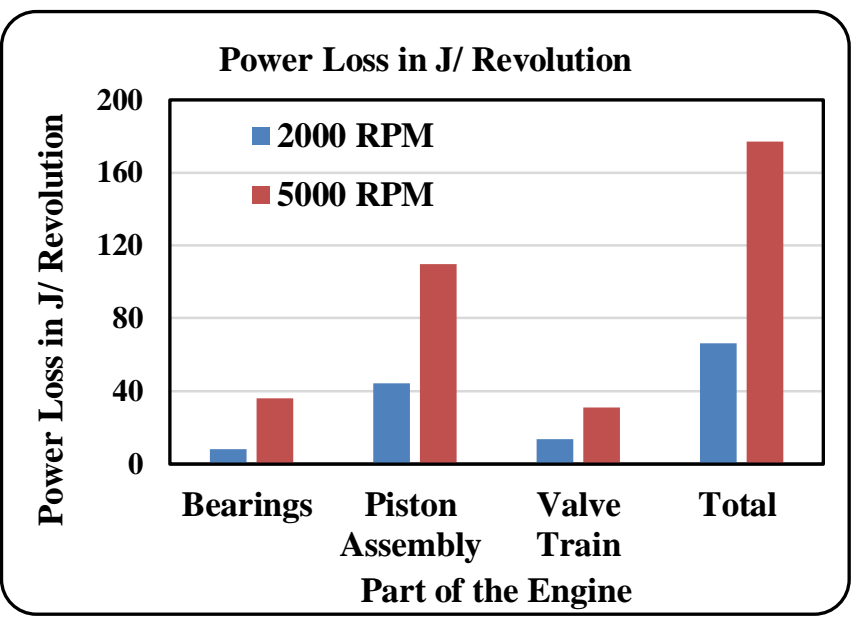

Figure 4: Power loss in J/Revolution Results for Ford Zetec 1.8 litter gasoline engine
Figure 5 summarizes the results from Shell obtained for the Mercedes Benz M111 2.0 litter gasoline engine at $2500 \mathrm{revs} / \mathrm{min}$. Results show the power loss for three types of engine oils, SAE 10W/30 $(v=67.5$ Centistokes), SAE 15W/40 ( $v=91$ Centistokes) and SAE 20W/50 $(v=172.3$ Centistokes $)$ at $40{ }^{\circ} \mathrm{C}$. When the viscosity is high as in case SAE $20 \mathrm{~W} / 50$, the oil flow is difficulty due to high resistance of oil to flow. This increase the power consumption and the pressure drop across the filters due to the increase in frictional losses [1]. As the results have been converted to FMEP (Frictional Mean Effective Pressure) [13-16], the FMEP for SAE 10W/30, SAE $15 \mathrm{~W} / 40$ and SAE $20 \mathrm{~W} / 50$ are $34.8,36.5$ and 37.7 $\mathrm{kPa}$ respectively. Higher values of FMEP resulted in higher power loss [1]. Through the valve train, the losses profiles are different due to the higher inertia forces that increasing the flow kinetic energy compared with shear forces that resist the flow.

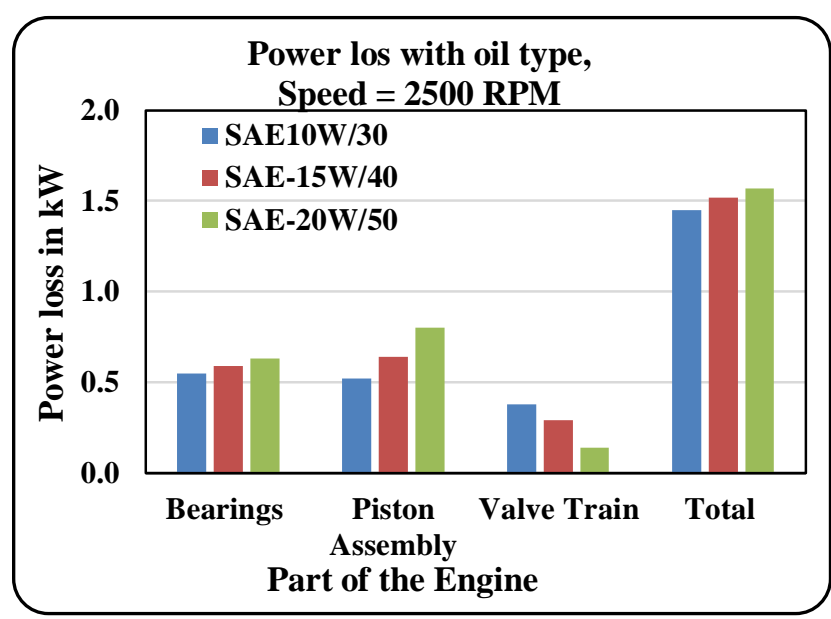

Figure 5: Results from Shell engine friction model for Mercedes Benz M111 2.0 litter gasoline engine at 2500 revs/min

Moore in [22] determined the general correlation function for fuel economy increase (FEI) which has the form:

$$
F E I=a-b . \eta-c . \mu-d . \alpha
$$

where $a, b, c$ and $d$ are constants, $\eta$ is a high shear viscosity, $\mu$ is a boundary friction coefficient and $\alpha$ is the pressure-viscosity coefficient. The boundary friction coefficient, $\mu$, is generally measured in a reciprocating friction rig (Moore uses the Plint TE77 High Frequency Friction Machine). The pressureviscosity coefficient, $\alpha$, is not always used in 
correlation functions, since it is not that straightforward to measure. Moore has reported correlation functions for the Sequence VI and VI-A engine tests [22-26]. For the Sequence VI engine test, the following correlation function is modified to get the Effective Fuel Efficiency Increase or decrease percentage $(E F E I \%)$ as:

$E F E I \%=8.647-1.252 \eta_{150}-15.62 \mu_{100}$

For the Sequence VI-A-engine test, his reported correlation function is:

$$
E F E I \%=6.238-1.697 \eta_{150}-4.051 \mu_{100}
$$

General Motors have reported that the following correlation functions are reasonably good across a wide range of their engines, Fuel Economy percentage $(F E \%)$ may be given as:

$\% F E=2.752-0.267\left(K I N_{100}\right)$

Where $\% \mathrm{FE}$ is the percentage increase in fuel economy relative to a $\mathrm{BC}$ reference oil, and $\mathrm{KIN}_{100}$ is the kinematic viscosity measured at $100^{\circ} \mathrm{C}$ as listed in Table 2.

Table 2 Engine oils viscosity values as obtained by the test compared with the manufacturer values

\begin{tabular}{|c|c|c|}
\hline $\begin{array}{c}\text { SAE } \\
\text { Viscosity } \\
\text { Grade }\end{array}$ & $\begin{array}{c}\text { Min. Viscosity } \\
\left(\mathrm{mm}^{2} / \mathrm{s}\right) \\
\text { at } 100{ }^{\circ} \mathrm{C} \text { as tabulated } \\
\text { by the manufacturer }\end{array}$ & $\begin{array}{c}\text { Min. Viscosity } \\
\left(\mathrm{mm}^{2} / \mathrm{s}\right) \\
\text { at } 100{ }^{\circ} \mathrm{C} \text { as } \\
\text { tested }\end{array}$ \\
\hline $0 \mathrm{~W}$ & 3.8 & 3.6 \\
\hline $5 \mathrm{~W}$ & 3.8 & 3.7 \\
\hline $10 \mathrm{~W}$ & 4.1 & 4.2 \\
\hline $15 \mathrm{~W}$ & 5.6 & 5.4 \\
\hline $20 \mathrm{~W}$ & 5.6 & 5.8 \\
\hline $25 \mathrm{~W}$ & 9.3 & 8.9 \\
\hline
\end{tabular}

Equation (6) was also modified as:

$\% F E=3.823-1.214($ HTHS $)$

Where HTHS: is the high temperature high shear viscosity measured at $150^{\circ} \mathrm{C}$ (Table 3 ). Table 3 listed the viscosity at both minimum and maximum viscosities measured. It has stable viscosity appropriate for low and high temperatures, which increases its ability to withstand high loads and work in warm climates.
Table 3 shows the viscosity values of engine oils. The error or uncertainty in calculating $\% \mathrm{FE}$ in equation (6) or (7) can be determined by differentiating \% FE with respect to $\mathrm{KIN}_{100}$ and HTHS to get

$\% \mathrm{FE}_{\text {error }}=-0.267\left(\mathrm{KIN}_{100}\right)$ error

or

$\% \mathrm{FE}_{\text {error }}=-1.214$ (HTHS) error

Table 3 Engine oils viscosity values at $100^{\circ} \mathrm{C}$ and the high shear viscosity measured at $150{ }^{\circ} \mathrm{C}$

\begin{tabular}{|c|c|c|c|}
\hline $\begin{array}{c}\text { SAE } \\
\text { Viscosity } \\
\text { Grade }\end{array}$ & $\begin{array}{c}\text { Min. } \\
\text { Viscosity } \\
\left(\mathrm{mm}^{2} / \mathrm{s}\right) \\
\text { at } 100{ }^{\circ} \mathrm{C}\end{array}$ & $\begin{array}{c}\text { Max. } \\
\text { Viscosity } \\
\left(\mathrm{mm}^{2} / \mathrm{s}\right) \\
\text { at } 100{ }^{\circ} \mathrm{C}\end{array}$ & $\begin{array}{c}\text { High shear } \\
\text { rate viscosity } \\
(\mathrm{mPa} . \mathrm{s}) \text { at } \\
150^{\circ} \mathrm{C}\end{array}$ \\
\hline 20 & 5.2 & 9.1 & 2.4 \\
\hline 30 & 10.3 & 11.5 & 3.1 \\
\hline 40 & 11.5 & 15.2 & 3.2 \\
\hline 50 & 16.0 & 20.5 & 3.8 \\
\hline 60 & 20.8 & 24.2 & 3.9 \\
\hline
\end{tabular}

Figure 6 summarizes the tested results of Tables 2 and 3.

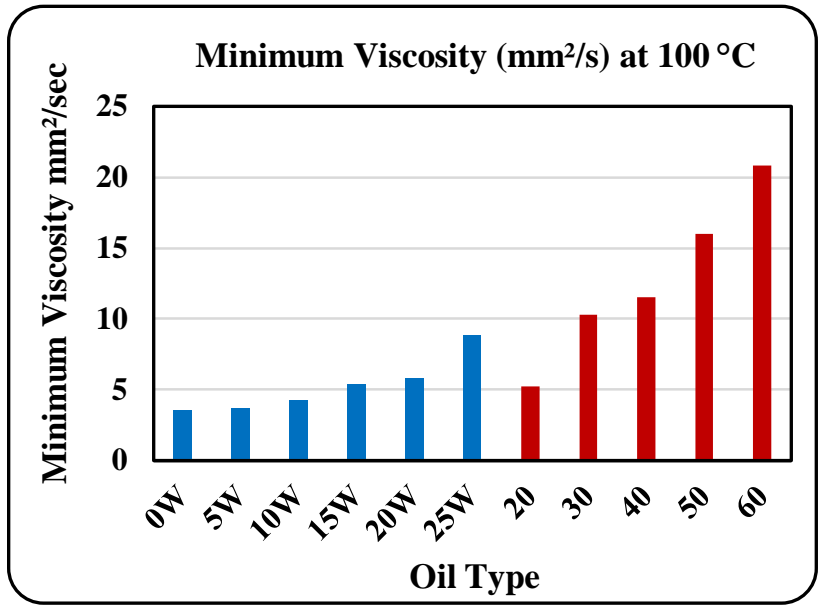

Figure 6: Different engine oils minimum viscosity in $\mathrm{mm}^{2} / \mathrm{sec}$ at $100{ }^{\circ} \mathrm{C}$.

Figure 7 shows the variance of motor oil viscosity values with oil type and temperature. It summarizes the data listed in Table 3. Figure 7 shows the viscosity where the ranges between the maximum and minimum limits are practically acceptable. As seen in Figure 7, while the variance in viscosity is significant, the high shear rate for the oils tested (at $150{ }^{\circ} \mathrm{C}$ ) is comparatively constant, which helps in 
extending the life of the engine despite temperature variations conditions.

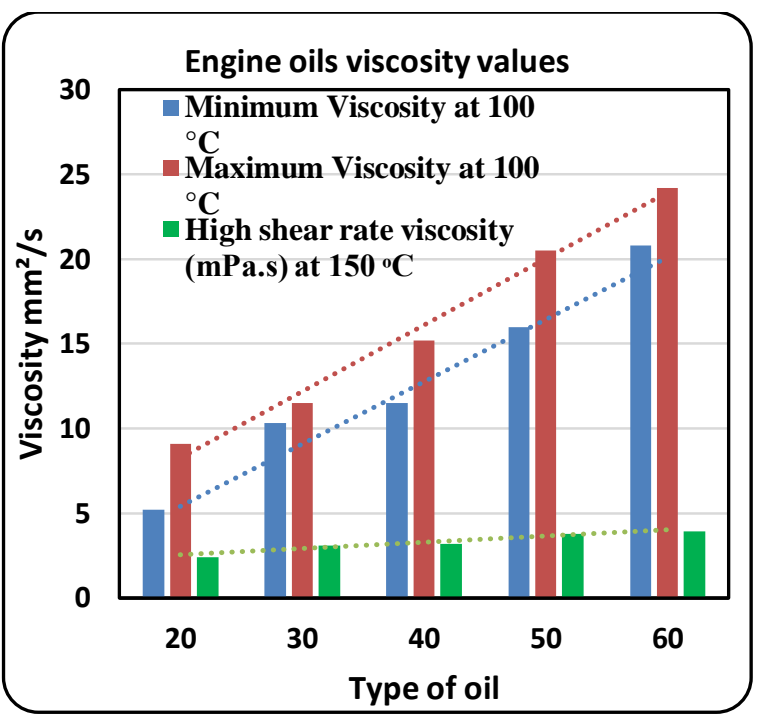

Figure 7: Engine oils viscosity values and the high shear rate for the oils tested

Figure 8 shows EFEI\% versus the oil viscosity for VI Engine. It shows the relation between function for fuel economy increase and the shear viscosity of the engine oil for VI engine.

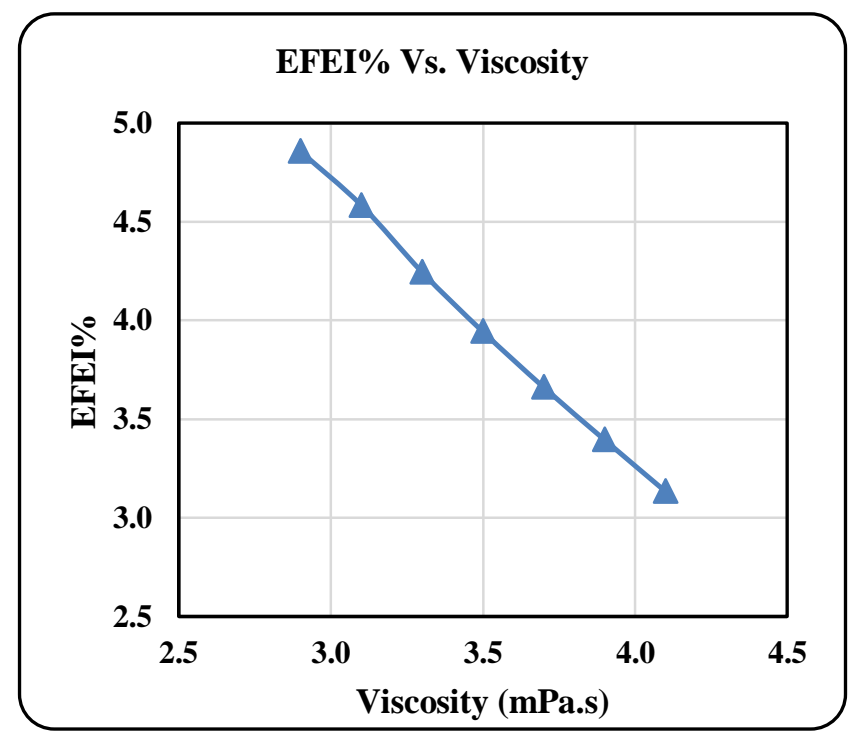

Figure 8: EFEI\% versus the oil viscosity for VI Engine

Figure 9 shows the relation between function for fuel economy increase and the shear viscosity of the engine oil for VI-A- engine.

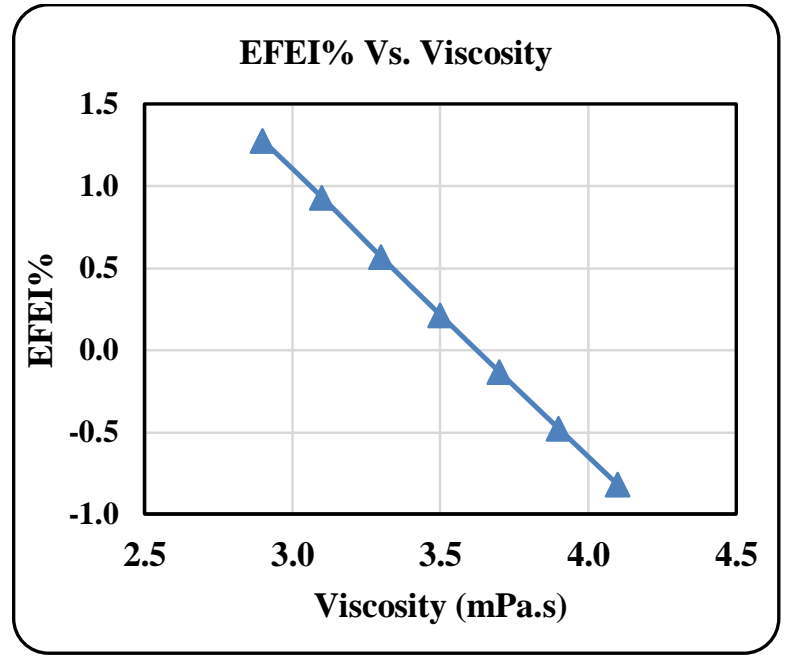

Figure 9: EFEI versus the oil viscosity for VI-A (related to correlated laboratory-scale tests with the wellestablished Sequence VI and VIA engine methods) Engine

Figure 10 shows the relation between percent FE\% versus the High Temperature High Shear (HTHS) viscosity.

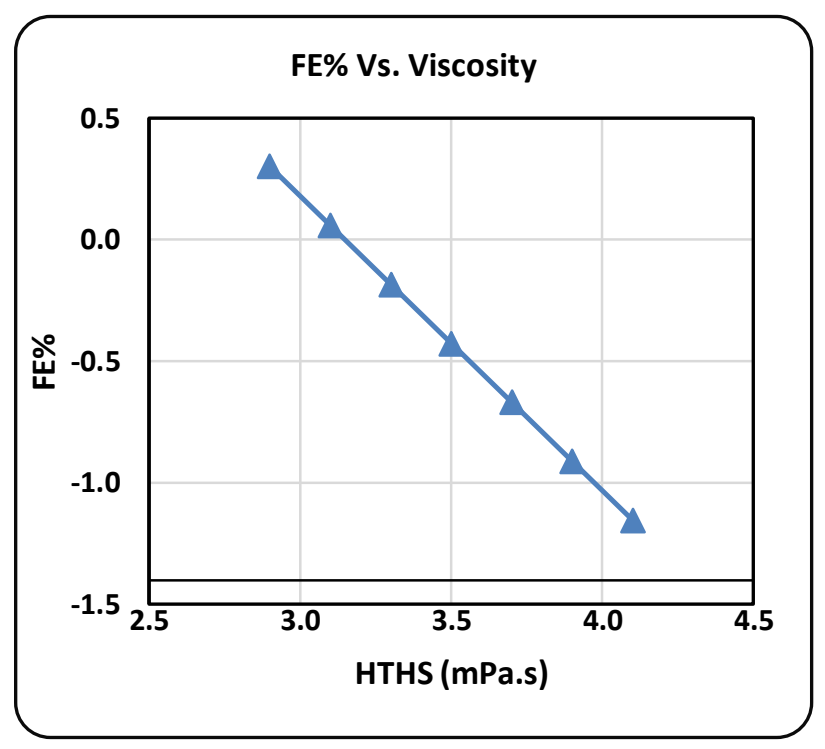

Figure 10: Relation between FE \% versus the high temperature high shear (HTHS) viscosity

It is clear that as the viscosity of the used engine oil increases the fuel economy and Effective Fuel Efficiency percentage are decreased in the normal conditions of the engine because more viscosity means more friction and so using the appropriate or suitable engine oil with specific viscosity will give the engine more dynamical free rotation or moving 
with good lubrications. As the viscosity of the engine oil increases EFEI\% for both VI and VI-A engines decreases and so the fuel economy (FE\%) decreases too as can be noticed from figure 8,9 and 10 so as a final result, follow the regulations of your car manufacturer and use the same engine oil standards which gives the car engine maximum output of mechanical work and protect your engine from wear and corrosion. Another issue, make to change your engine oil periodically because its viscosity is a function of temperature (as shown in table 3 and figure 7) and also with time, its value goes down and so the coefficient of viscosity of such oils are reduced which increases wear in the engine and lubrications become low.

\section{Conclusions}

Internal combustion engines are widely used in vehicles. It is important for the car that; the engine performs its proposed work properly. There are bunches of technologies that can be worked on to display the work of the engines, such as vibration test, acoustic test. All of these tests were done by observing the oil and ordering its characteristics. Oil inspection and control are the best way to check engine safety. From the $\mathrm{pH}$ test, it is clear that the car's age builds the steps for successive corrosive increases and pollution also increase. The following are the main concluding points:

1. The function to fuel economy EFEI\% is linearly decreased by the increase in shear viscosity of the engine oil, also the Fuel Efficiency FE\%.

2. While the variance in viscosity is significant, the high shear rate for the oils tested (at $150{ }^{\circ} \mathrm{C}$ ) is comparatively constant, which helps in extending the life of the engine despite temperature variations conditions.

3. Higher values of FMEP resulted in reducing efficiency and increasing power loss.

\section{References}

[1]Anthony Esposito, Fluid Power with Applications, 7th Edition, published by Prentice Hall, 2008

[2] Jafar M. Hassan \& Saif Yousif Ibrahim. An Experimental Study into the Effect of Temperature and Pressure on the Hydraulic
System, 2009, Journal. Tech \& .Eng. Vol. 27. No. 12, PP. 2531-2545.

[3] Jean-Louis Ligier and Bruno Noel, Friction Reduction and Reliability for Engines Bearings, Lubricants 2015, 3(3), pp. 569-596

[4] John J.Truhan, JunQu and Peter J.Blau. The effect of lubricating oil condition on the friction and wear of piston ring and cylinder liner materials in a reciprocating bench test, 2005, Wear, Volume 259, Issues 7-12, pp. 1048-1055.

[5] Muhammad Afiq Bin Zali, "Lubrication Oil System Design For A New 4-Strokes Single cylinder Engine Cylinder Head", PhD. Thesis, University Malaysia Pahanga001061-2009.

[6] Eraldo Jannone da Silva, Eduardo Carlos Bianchi, João Fernando Gomes de Oliveira, Paulo Roberto de Aguiar, The Inlet Engine Valves Grinding Using Different Types of Cutting Fluids and Grinding Wheels, 2002. Mat. Res. vol.5 no.2, pp.187-194

[7] Andrej Lenert, Youngsuk Nam, and Evelyn N. Wang, Heat Transfer Fluids, 2012, Annual Review of Heat Transfer Vol.15, pp. 5-25.

[8] S. M. Ashrafur Rahman, T. J. Rainey, Z. D. Ristovski, A. Dowell, M. A. Islam, M. N. Nabi, R. J. Brown, Review on the Use of Essential Oils in Compression Ignition Engines, 2019, In book: Methanol and the Alternate Fuel Economy, PP. 157-182

[9] Stone, R. Introduction to internal combustion engines, 3rd edition, 1999 (Palgrave, New York).

[10] Raadnui, S. and Meenak, A. Effects of refined palm oil (RPO) fuel on wear of diesel engine components. Wear, 2003, 254, 1281-1288.

[11] Sang Myung Chun, "Simulation of engine life time related with abnormal oil consumption", Tribological International, 2009, 44, pp. 426436.

[12] Wensheng Wang, Yongchun Cheng, Guojin Tan and Jinglin Tao, (2018), Analysis of Aggregate Morphological Characteristics for Viscoelastic 
Properties of Asphalt Mixes Using Simplex Lattice Design, materials, Materials, Vol. 11, No. 10, 1908, pp. 1-20.

[13] A. L. Nagy, J. Knaup, I. Zsoldos. Investigation of Used Engine Oil Lubricating Performance through Oil Analysis and Friction and Wear Measurements. - Acta Technica Jaurinensis, Vol. 12, No. 3, 2019, pp. 237-251

[14] Li Du and Jiang Zhe, "A high throughput inductive pulse sensor for online oil debris monitoring", 2009, Tribological International, 44, pp. 175-179.

[15] A. Wolak. Changes in Lubricant Properties of Used Synthetic Oils Based on the Total Acid Number. Measurement and Control 2018, Vol. 51(3-4) 65-72.

[16] Margareth Judith Souza de Carvalho et al, "Lubricant viscosity and viscosity improver additive effects on diesel fuel economy", 2010. Tribological International, 43, pp. 2298-2302.

[17] A. Albarbar et al. "Diesel engine fuel injection monitoring using acoustic measurements and independent component analysis", 2010. Measurement, 43, pp.1376-1386.

[18] AZO Network (2016). A Guide to Measuring Oil Viscosity. UK.

[19] B. Tesfa et al. "Prediction models for density and viscosity of biodiesel and their effects on fuel supply system in CI engines", 2010, Renewable Energy 35, pp. 2752-2760.

[20] Hojat Ahmadi and Kaveh Mollazade. "Oil Condition Monitoring Technique for Fault Diagnosis on Crane Liebherr LHM-1200", 2009. Applied Engineering Research, Volume 4 Number 4, pp. 557-569.

[21] S.Korcek \& M. Nakada. "Engine Oil Performance Requirements \& Reformulation for Future Engines \& Systems", 1995, Proceedings of the International Tribological Conference, Yokohama, p 783.

[22] R.I. Taylor \& R.C. Coy, " Improved Fuel Efficiency by Lubricant Design: A Review"
Shell Research \& Technology Centre, Thornton, P.O. Box 1, Chester, CH1 3SH, UK.

[23] M. Yamada. "Fuel Economy Engine Oils: Present \& Future", 1996, Jap. J. Trib., 41, No. 8, p783, 1996.

[24] J.G. Damrath \& A.G. Papay. "Fuel Economy Factors in Lubricants", 2000, SAE 821226.

[25] W.J. Bartz, "Fuel Economy Improvement by Engine \& Gear Oils", 5th CEC International Symposium: Performance Evaluation of Automotive Fuels \& Lubricants, CEC97-EL19.

[26] S. Furuhama. "Tribology of Reciprocating Internal Combustion Engines", 1987, Jap. Soc. Mech. Engrs Int. J., 30, No. 266, p 1189.

\section{Contribution of individual authors to the creation of a scientific article (ghostwriting policy)}

Mohannad O. Rawashdeh: share in preparing and writing the introduction and objectives of the study.

Sayel M. Fayyad: mathematical modeling and data manipulation and extract results.

Ahmad S. Awad: reviewing and evaluating the results, the discussion and the article editing and rewriting. 